\title{
The Transformation of Vernacular Architecture in Indonesia in Relation to Colonisation By the Dutch
}

\author{
Saskia Vogelsang ${ }^{1}$ \\ Bachelor Degree of Architecture Study Program \\ Jade Hochschule Wilhelmshaven/Oldenburg/Elsfleth \\ Germany \\ s.vogelsang277@gmail.com
}

\begin{abstract}
During my semester abroad at the Udayana University in Denpasar, Bali, I increasingly felt the need to deal with the culture, lifestyle and way of life of Indonesians, among other things with regard to their housing situation. During my studies at the university I realized that the colonization of the Dutch had an influence on the life of the locals and I asked myself to what extent the colonization had an influence on the architecture. In class I learned a lot about traditional buildings in Indonesia, during an excursion to Taman Nusa, an Indonesian Culture Park, I was able to examine them personally and draw comparisons. In everyday life, however, I have seen very little of such architecture in and around Denpasar and therefore wanted to gain an understanding of its development. In order to be able to deal with the topic, I first of all dealt with what transformation means to me, especially in relation to architecture. I also dealt with colonization and its temporal implications for Indonesia. It was important for me to find out what influence the Dutch had on Indonesian lifestyles during the years of upheaval and what changes there were in architecture as a result. In conclusion, the results were that the influence on architecture might not necessarily be a transformation, but that architecture was replaced by Western structures and then further developed to adapt it to the circumstances. This results in a new understanding for the current architecture in cities and also for the fact that vernacular architecture is not to be found in these.
\end{abstract}

\section{Index Terms - Colonisation, Replace, Transformation, Vernacular Architecture}

\section{INTRODUCTION}

The elaboration on the topic The Transformation of vernacular Architecture in Indonesia in relation to colonisation by the Dutch confronts one with the confrontation with what transformation means, how to define vernacular architecture, where this architecture can be found and what it is. In addition, the question of what is meant by colonization, when was colonization located in the area under discussion, and, above all, what connection these individual themes have with each other is inevitable.

What parallels, differences and connections exist between the individual themes and what influence do they have on each other? As a result of this elaboration, I would like to deal with these issues and clarify this question.

\section{RESULT AND ANALISYS}

\section{A. The Meaning of Transformation}

The term transformations in connection with architecture has a very personal and individual meaning for me. During 
the first two semesters of my studies, I dealt almost daily with the concept and its meaning.

As new students, we were already confronted with the term during the week before the course and asked to develop our own definition. What is transformation? What does transformation bring about? What can it be used for?

The term transformation was familiar to me at that time, but I never dealt with its definition. In the Oxford Dictionary, the term is defined as "a complete change in the appearance or character of something or someone, especially so that thing or person is improved. It comes from the Latin of "transformare", which has the direct translation "transformation" or "change".

While everyday life is mostly about the transformation of appearance in general, such as a haircut, a hair color or a new clothing style, our studies were about the development process in finding architecture. How was the planned further development possible? How does the step from drawing to model work, how did it look the other way around? Many projects and developments later, I could see the meaning of the course, which was a combination of drawing, representation and design. It was about recognizing the process conveyed through various skill exercises. For my later professional life I already know that this examination of the different methods will take me further, as I already integrate certain procedures in the course of my studies.

In the course of this elaboration, I would therefore like to deal further with the topic of transformation in architecture.

\section{B. Transformation of Architecture}

In short, one can say that transformations in architecture cover different tasks. Transformations can already be applied in the development process of a design, in which the created one is further developed until it corresponds to what one imagines as an architect or as a client.

However, this paper deals with the transformation of architecture through external influences. Architecture has developed again and again over the last centuries, it has been transformed. Different types of architecture are constantly being discovered on different continents. Architecture is influenced not only by climate, but also by cultural and ethnic influences. While there are countries on earth where people still live in simple huts, there have been skyscrapers and towers in other countries for decades, the top of which can only be guessed from the ground with the naked eye. Architecture always develops, in the last 50 years, today, tomorrow and also in the next hundred years. Before, after, it will always develop.

\section{Colonisation and what It Means for Indonesia}

The question arises as to what the colonization of Indonesia has to do with this and how it influences the development of architecture, especially with regard to vernacular architecture, which will be explained in more detail later. What does colonization mean?

Colonization, colonisation refers to the development of a natural area that has not been used by humans until now and the subjugation of a territory including the population living there as a colony. The first direction is connected with the expansion of human settlement areas into primeval forests, moors, tundra and similar natural areas that are difficult to use. This process is referred to as internal or inland colonisation. In contrast, external colonisation refers to the establishment of colonies outside the existing state.

Colonialism is an approach in which one people subordinates itself to another. The word colonialism comes from the Latin, it is a derivation of the word 'colonus', which means farmer.

From this the practice developed to migrate with a tribe into a new area and to settle there. The further political solidarity to the homeland is to be emphasized here however despite permanent settlement. In return there is the word empire, which is often mistakenly also used. Empire also comes from the Latin imperium and means to dominate. Rather, this means domination over a conquered territory. In both cases it is political and economic control over a dependent territory

\section{How Took Colonisation Place in Indonesia?}

The first settlement of the Indonesian islands took place already in the 16th century by the Dutch, almost 350 years (1598-1948) the Dutch settled the area and advanced their trading power[5]. In the year 1596 the first settlement of the island Java was made and the city Bantan, at the west coast of the island was taken. While the English took the north of the island of Sumatra in 1602, the Dutch increasingly became the rulers of the region and displaced the Portuguese to the east of the island. Only in short periods of time could other powers take over the island, but they were displaced again by the Dutch. During the Second World War, however, the Netherlands lost its position of power over the Japanese and consequently developed Dutch India.

In 1602, the VOC (Vereenigde Oostindische Compagnie; engl. United East India Company) was granted the monopoly of trade between the Cape of Good Hope and South America. In 1607, the island of Ternate, previously inhabited by the Spanish, was divided. The expansion of the Netherlands as a trading and colonial power began in the seventeenth century, when the Vereenigde Oostindische Compagnie) and later the WIC (West-Indische Compagnie; engl. West India Company) established trading posts in the East (Dutch - East India, South Africa, Japan) and West (the Caribbean, South and North America, and the coast of West Africa), as shown in fig. 1. During the sixteenth and seventeenth centuries, the United East India Company and later the West India Company maintained trading posts in North America (Nieuw Amsterdam, now New York), the Berbice River in Guyana, Brazil, the Cape of Good Hope, the African West Coast, present-day Sri Lanka, Japan and the Indonesian archipelago. Under Dutch administration came Dutch - East India, Suriname and some islands in the Caribbean. Dutch - East India was a Dutch colony until 
1949, Suriname was under Dutch administration from 1645 to 1976 . The Netherlands is particularly well known for the settlement of todays Indonesia. On the ruins of the conquered Jakartas, Java, a meeting point for the Asian area was established. In 1611 the VOC settled in Jakarta, and in 1619 the town of Batavia, renamed after the VOC, was finally taken over. From here spices were traded with the world for the beginning, later the focus was set on the cultivation of coffee. For this purpose tea and coffee were imported from India and plantations were established in Java. The aim of the VOC was to establish a monopoly of the spice trade.

The independence of Indonesia proclaimed on 17 August 1945 was not recognised until 27 December 1949. The cultural and social diversity, the lack of standardized education and the total lack of organization shook the new independent state of Indonesia.

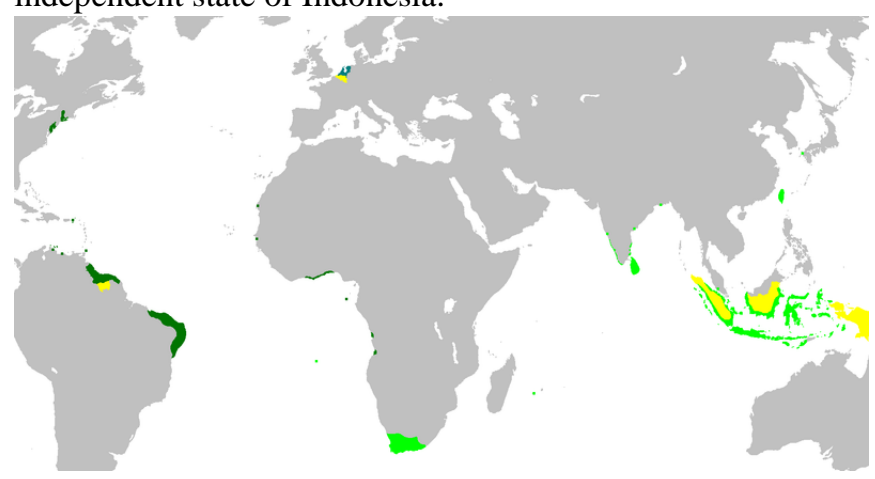

Fig. 1. The Dutch colonial empire 1598-1975

\section{E. Vernacular Architecture}

The term vernacular architecture describes building constructions and building methods in which local materials and building traditions are used to fulfil concrete building tasks.

The term can be used in today's language to describe historical building forms that are no longer erected in this form today. Vernacular architecture is also referred to as regional architecture or traditional architecture, which also means today's buildings erected in traditional architectural language.

In general, these are forms and constructions which, based on the needs and habits of the people, have developed as a result of locally available materials and the climatic conditions, have been passed on over centuries and modified slightly or more strongly. They are not architectural inventions in the narrower sense of the word, but rather buildings could be described as types or typologies. Moreover, this building is not primarily interested in form, but rather in three criteria that are central to the exhibition: First, that the creation of spaces for human communities is a central concern of vernacular building, second, that it is closely related to nature and does not see it as a contradiction to architecture, as is often the case in modern architecture and finally that the materials used are primarily clay, wood or stone, which are available locally.

\section{F. Vernacular Architecture in Indonesia}

Indonesia's architecture reflects the diversity of cultural, historical and geographical influences that have shaped Indonesia as a whole. Intruders, colonizers, missionaries, merchants and traders brought about cultural changes that had profound effects on architectural styles and techniques. Throughout the archipelago, numerous Indonesian folk houses have been built. The traditional houses and settlements of Indonesia's several hundred ethnic groups are extremely diverse and have their own history. The houses have social significance in society and demonstrate local ingenuity in their relationships with the environment and spatial organization. Ethnic groups in Indonesia are often associated with their own distinctive form of Rumah Adat. As shown in fig. 2 and fig. 3 Rumah Adat houses are traditional houses in Indonesia in general. They have different characteristics depending on the region and differ in size, shape, roof shape and finish. The houses are at the centre of a network of customs, social relations, traditional laws, taboos, myths and religions that hold the villagers together. The house is the focal point for the family and its community and is the starting point for many of the activities of its inhabitants. Traditional or vernacular homes of Indonesians area unit the most effective illustration of their endemic culture. Called the Rumah Adat, these homes varied across regions and cultures however conjointly had bound similarities. They were manufactured from fibre, bamboo and sound property and had sloping roofs. Designed to adapt to Indonesia's hot and wet climate, these homes were created on stilts, that protected product from moisturizing and reduced the chance of water-borne diseases. The most strength of those stilt-houses lay in their ability to soak up shock waves. The standard applies to a post, beam and lintel construction system that brings the load directly to the ground with either wood or bamboo walls that are not load-bearing. Traditionally, tenon joints and wooden pins are used instead of nails. Natural materials - wood, bamboo, straw and fibres - form rumah adat. The traditional house of Nias has post, beam and lintel construction with flexible nail-free joints, and non-bearing walls are typical of Rumah Adat. The different examples show the variance of these houses and the different regions.

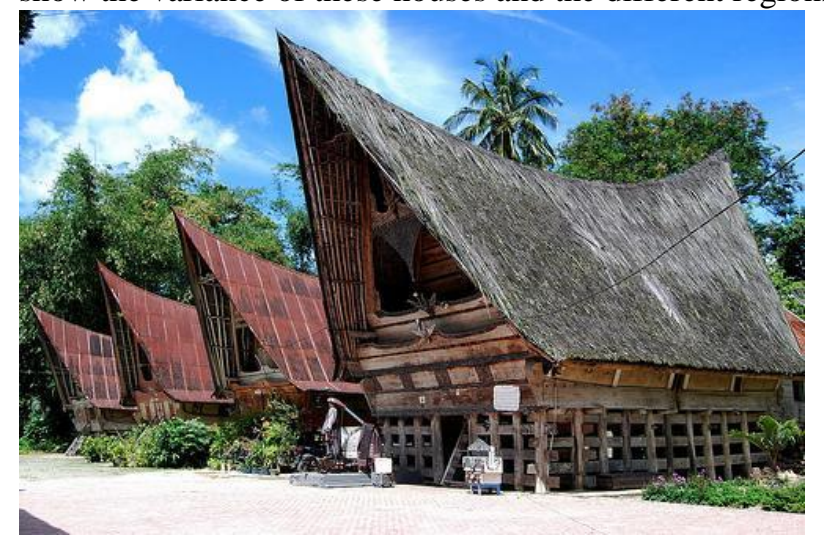

Fig. 2. Rumah adat: Batak Toba Houses, Lake Toba, Indonesia. The 
picture shows a row of the typical Rumah adat houses, their roof form sets itself off optically from the roofs built today in western regions of the world.

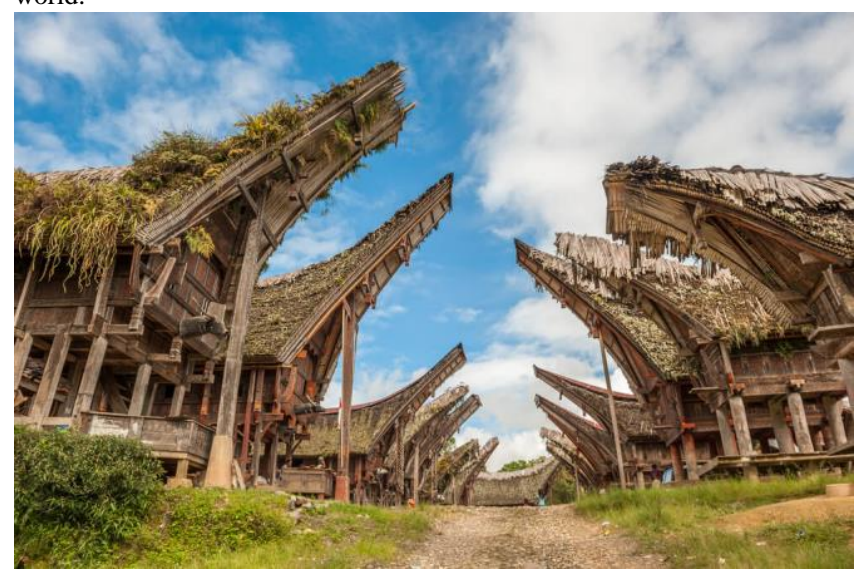

Fig. 3. Rumah adat: Tana Toraja. Another representation of a traditional village in the style of the Rumah adats also shows the very special roof shape and the construction with stilts. https://www.seva.id/blog/tradisi-pemakaman-harga-sultan-ala-tana-toraja$\underline{102019 /}$

\section{G. Influences on Indonesian Architecture}

At the beginning of colonisation, the Dutch used urban structures from their European homeland; for example, the city of Batavia, illustrated in fig. 4 and fig.5, with its canals and canal houses, was very similar to the old city of Amsterdam. For almost two centuries, the colonists have done little to adapt their European architectural habits to the tropical climate. The building style was closed at first without paying attention to ventilation and insulation, but later people started to look at the local building and the style was much better adapted to the tropical conditions. Although houses, ducts and enclosed solid walls were initially designed as protection against tropical diseases from the tropical air, the Dutch later learned to adapt their architectural style with local building elements (long eaves, verandas, porticoes, porticoes, large windows and vents).

Consequently, there was a reversal that changed the style of architecture in Indonesia:

"The Indonesian and Dutch cultures became mixted and a kind of mestizo culture was established which is called Indische culture. The word Indische refers to IndoEuropeans of mixed Dutch-Indonesian blood, but it is also used for mixtures of cultural elements (...) This Indische culture is not Dutch, nor yet Indonesian, and was fostered by the contacts of the Dutch with the Indonesian official classes, the priyayi, in the public domain and with the Indonesian concubine, the nyai, in the private domain. The Indische culture has greatly influenced both the Dutch and the Indonesians and has achieved a certain degree of homogeneity through this. (...) The Indische culture implied a spacious life-style and induced the Indische town."

This Indian culture was expressed structurally in a new kind of house building, the Indian house. The Indian House is characterized by a generous and pompous architecture. There is talk of a manor house, which is decorated by typical Javanese roof forms. It also has large gardens, galleries and verandas. Also many Javanese construction elements can be found. The architecture of Java was further developed and extended by modern western design and construction elements. The cosmological spatial concept of the Javanese house naturally had a completely different background. The ordinary, genuine Indian houses are now very open and furnished according to the Indonesian model, but still preserve this classicist style. At the front there is a living gallery with columns supporting a high hipped roof and behind it the actual house with a central gallery and a rear gallery. The roofs themselves are covered with Dutch tiles, which are still popular in Indonesia. The galleries are increasingly losing their stately classicist character. They receive an additional front gallery clad with corrugated iron and sometimes thin iron columns. After 100 years, the idea of classical forms and quality has completely faded

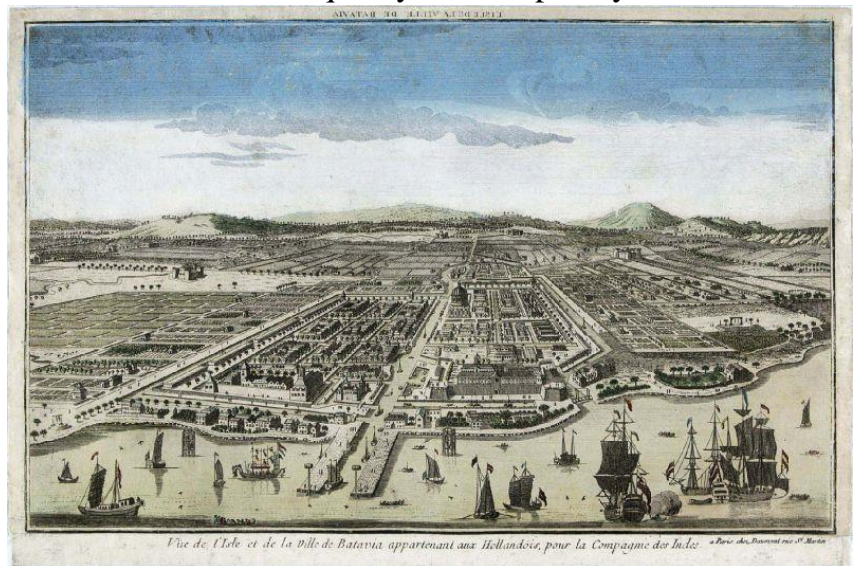

Fig. 4. Batavia, the old city of Jakarta, as it was built by the Dutch. The illustration shows the comparison to the Dutch city of Amsterdam, the canals run through the city as they are typical for the Dutch capital. https://www.ikons.id/akhir-riwayat-batavia-di-utara-jakarta/

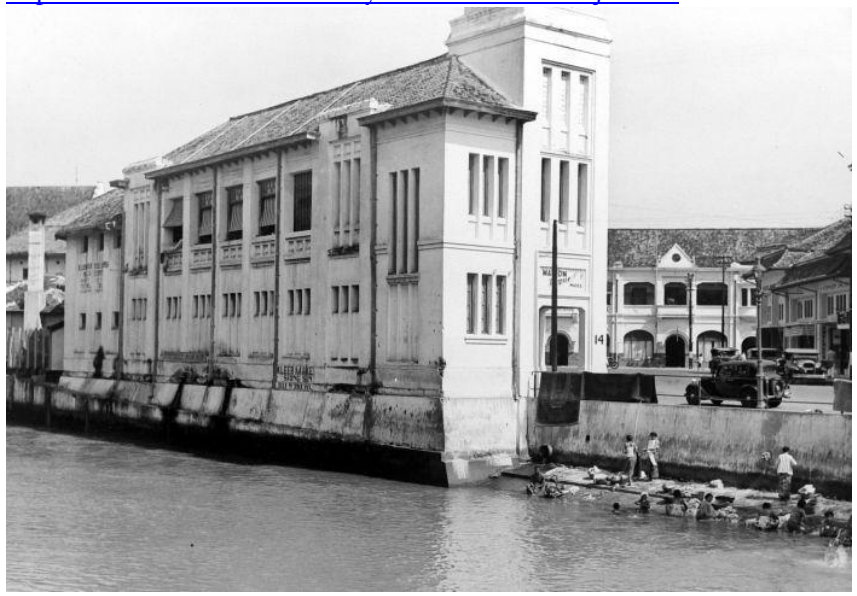

Fig 5. Pasar Baru, Postweg, a colonial building on one of the canals of the old town of Bavaria, which was later renamed Jakarta https://www.skyscrapercity.com/showthread.php?t=1227949\&page=4

\section{H. Is There a Transformation or a Replacement By Dutch Architecture? an Outlook}

While the style of Netherland cities influenced the architecture through colonisation, the image of traditional buildings in cities disappeared increasingly for the time 
being and even today hardly any such houses can be found in the urban area. The obvious assumption for this is that in a small area much larger and more densely populated areas could be created by the Netherland architectural style. The cityscape of today's cities resembles that of Western cities in many respects and gives rise to the assumption that the development of the local architecture is not a transformation of the Indonesian architectural style, but a replacement of traditional houses. In urban areas, as you can find in the Netherlands, stone, steel and concrete are used, while only a few elements are made of bamboo or wood. Roofs are also covered and no longer often have the typical charm of South-East Asian architecture. But since the architectural style has evolved from traditional to more modern, many houses are struggling to withstand the humid, warm climate.

The question is no longer whether there has been a transformation or a replacement, but whether the transformation of architecture in these countries is good. If one crosses the large cities of Indonesia, one notices that many to almost all buildings are very dilapidated. In contrast to European or generally Western countries, buildings in Indonesia are rarely renovated or refurbished. Many buildings are neglected until they are no longer usable and ready for demolition. After the plots are free again, they are often rebuilt in the same style and the period of the disintegration of the structures of the building begins. It is reasonable to assume that knowledge about the correct handling of the maintenance of buildings has not yet made its way into Indonesia, or has done so too little.

It can be seen that the adoption of the western architectural style is initially an advantage that offers Indonesians other ways of protecting themselves from the sun and animals, among other things. Over the years, however, it has become apparent that the locals have not without reason developed certain building styles to withstand precisely the conditions that the weather brings with it, and these findings have increasingly changed the elaboration of the Western style. The buildings, which were kept closed for the time being, were adapted to the climate and opened and thus better ventilated. Even today it can still be seen that the construction of houses made of stone and concrete works, but not well. Many houses show large mold problems, which are promoted by the high air humidity in to closed areas. The lessons learnt from traditional architecture are thus introduced but not always sufficiently implemented.

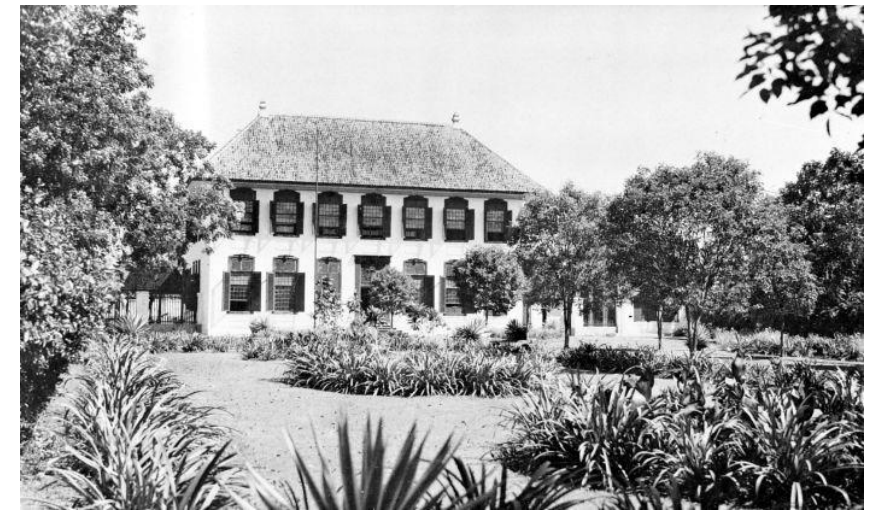

Fig. 5 National Archives Museum around 1760, Jakarta. The picture shows the old residential house built in Colonial Sil, the private residence of Governor. General Reinier de Klerk, which is now used as the National Archives Museum.

https://www.skyscrapercity.com/showthread.php?t=1227949\&page=4

\section{CONCLUSION}

Finally, it is difficult to assess the extent to which the Dutch have intervened in the development of contemporary architecture in Indonesia. It is obvious that the Indonesians have tried in many aspects and try to maintain their traditional style. Many buildings are artfully decorated, ornamentation decorates doors, entire entrance areas are painted golden, ornamentation is particularly prevalent among wealthy families. The family temples are also very splendidly decorated. On the other hand, it is becoming increasingly rare to see Indonesians clinging to the more important construction elements such as stilts. The architectural style in Indonesia is due to the climatic conditions not at all as comprehensible as it can be found in western countries.

Nevertheless the question arises to what extent the architecture would have developed in the last centuries, if there had not been the settlement by the Europeans, in particular by the Dutch. The colonisation has pushed forward the expansion of the knowledge of building materials, it could well be that building materials such as probation would not have been able to enter the country without them and that the dimensioning of the buildings would still be limited to bamboo and wood. Due to the population growth it was very important to create enough living space, the architecture had to develop to create enough living space. On the other hand, the population could only multiply through the development of architecture. In rural regions the Indonesians still live much easier, in poor regions simple wooden or bamboo buildings are not uncommon. If one does not have the possibility to remedy the climatic conditions by technology such as air conditioning it is however also very important to provide sufficient lighting and ventilation of the houses, which is very well possible with the traditional architectural style like that of the Rumah Adat. In the cities, on the other hand, there are more "modern" elements to be found, wood and bamboo seem to have been largely replaced by stone, 
concrete and steel. At this point I ask myself whether this development would have made it to the islands of Indonesia without colonization. The assumption suggests itself that the development that has taken place to this day would not have taken place if the Dutch and today's tourism had not contributed to it. This is intensified if one takes a look at parts of Indonesia that are clearly away from tourism, as it can be found on the island of Bali, for example. Away from heavily populated areas, there's a much less developed infrastructure, houses with few modern moves. Consequently, not everything that the Dutch have brought to Indonesia seems to be bad. If the architectural elements were not an improvement, the Indonesians would probably have returned to their traditional architecture much earlier. However, since this is not the case in the more prosperous areas, it seems to be an improvement. In addition, it seems difficult to use the traditional architectural style in urban areas today, it is difficult to integrate into the cityscape and takes up much more space than today's architectural style.

If we look at the question of whether vernacular architecture is still being built today, we can only confirm this for rural and poor regions. Far away from mass tourism, there are still traditional settlements that still use the Rumah adat architectural style today and accordingly create living conditions without much technology that make the climate more bearable. Despite these commendable efforts to define Indonesian architecture through inspiration from indigenous elements of Indonesian architecture and traditions, the practice and results may not meet expectations. Sometimes the result is mediocre, criticised as a superficial addition to modern building - using only traditional ornaments or simply attaching traditional roofs.

\section{REFERENCES}

[1] Nas, Peter J.M., "The Indonesian City. Studies in Urban Developing and Planning". 1986.

[2] Markus Zahnd, "Traditionelle Stadtquartiere in Semarang und Yogyakarta", Indonesien, Teil 